\title{
Clinical pharmacology of morphine in infants and children
}

\author{
Gian Maria Pacifici \\ Associate Professor of Pharmacology, via Sant'Andrea 32, 56127 Pisa, Italy.
}

Corresponding Author: Gian Maria Pacifici, Associate Professor of Pharmacology, via Sant'Andrea 32, 56127 Pisa, Italy.

Received date: November 25, 2021; Accepted date: November 30, 2021; Published date: December 18, 2021

Citation: Gian M Pacifici (2021) Clinical pharmacology of morphine in infants and children. J. Pharmaceutics and Pharmacology Research. 4(5); DOI: $10.31579 / 2693-7247 / 053$

Copyright: ( $)$ 2021, Gian Maria Pacifici, This is an open access article distributed under the Creative Commons Attribution License, which permits unrestricted use, distribution, and reproduction in any medium, provided the original work is properly cited.

\begin{abstract}
Morphine is used to treat pain, for treatment of opioid dependence, and neonatal abstinence syndrome. Morphine is modestly absorbed from the gastrointestinal tract whereas after rectal administration, by intranasal or buccal application morphine is well absorbed. Morphine is eliminated by glomerular filtration and by conjugation with glucuronic acid; morphine-3glucurinide and morphine-6-glucurinide are the main metabolites and the last has analgesic effect. In infants, morphine is used to treat severe or sustained pain, sedation, and pain relief. In children, morphine is used to control pain and morphine may be administered by subcutaneous or intravenous injection, orally, by rectum, or by continuous subcutaneous infusion and morphine dose varies according to the child age. Morphine has been found efficacy and safe in infants and children but may induce adverse-effects. The effects caused by morphine and the treatment with morphine have been studied in infants and children. In newborns, morphine elimination half-life ranges from 7.7 to 13.5 hours and decreases with infant maturation. In newborns, infants and children, the total body clearance of morphine ranges from 14.5 to $71.1 \mathrm{~L} / \mathrm{h} / 70 \mathrm{~kg}$ and increases with infant maturation and child development. Morphine is transported in the human brain, poorly crosses the human placenta and accumulates in breast-milk. The aim of this study is to review the published data on morphine dosing, efficacy and safety, effects, adverse-effects, pharmacokinetics, metabolism, drug interaction, treatment, transport into human brain of infants and children and morphine transfer across the human placenta and migration into the breast-milk.
\end{abstract}

Running title: Morphine in infants and children.

Key words: morphine; dosing; efficacy and safety; effect; adverse-effects; pharmacokinetics; metabolism; drug interaction; treatment; brain; placenta; Brest-milk; infants; children.

\section{Introduction}

\section{Mechanism of opioid-induced analgesia}

The analgesic actions of opiates after systemic delivery represent actions in the brain, spinal cord, and in some instances the periphery.

\section{Supraspinal actions.}

Microinjections of morphine into a number of highly circumscribed brain regions will produce a potent analgesia that is reversible by naloxone, a $\mu$ opioid receptor antagonist (MOR). The best characterized of these sites is the mesencephalic periaqueductal gray (PAG) region. Several mechanisms exist whereby opiates with an action limited to the PAG may act to alter nociceptive transmission. MOR agonists block release of the inhibitory transmitter $\gamma$-aminobutyric acid from topically active PAG systems that regulate activity in projections to the medulla. PAG projections to the medulla activate medullospinal release of norepinephrine and serotonin at the level of the spinal dorsal horn. The release can attenuate dorsal horn excitability. Interestingly, this PAG organisation can also serve to increase excitability of dorsal raphe and locus coeruleus from which ascending serotoninergic and noradrenergic projections to the limbic forebrain, respectively, originate. Aside from direct supraspinal effects on forebrain structures, these limbic projections provide a mechanism for the effects of opiates on emotional tone [1].

\section{Spinal opiate actions.}

A local action of opiates in the spinal cord will selectively depress the discharge of spinal dorsal horn neurones evoked by small high-threshold but not large (low-threshold) afferent nerve fibres. Intrathecal administration of opioids in animal ranging from mice to humans will reliably attenuate the response of the organism to a variety of somatic and visceral stimuli that otherwise evoke pain states. Specific opiate receptors are largely limited to the substantia gelatinosa of the superficial dorsal horn, the region in which small, high-threshold sensory afferent show their principal termination. A significant proportion of these opiate receptors are associated with small peptidergic primary afferent $\mathrm{C}$ fibres; the remainder are on local dorsal horn neurons. Spinal opiates act on spinal receptors located presystemically on small, high-threshold primary afferents to prevent the opening of voltage-sensitive $\mathrm{Ca}^{2+}$ channels, thereby preventing transmitter release from those afferents. A postsynaptic action is demonstrated by the ability of opiates to block excitation of dorsal activation of dorsal horn projection neurons partly by 
hyperpolarizing the neurons through the activation of $\mathrm{K}^{+}$channels, such that the membrane potential more closely approximates the equilibrium potential for $\mathrm{K}^{+}$. The joint capacity of spinal opiates to reduce the release of excitatory neurotransmitters from $\mathrm{C}$ fibres and to decrease the exatibility of dorsal horn neurons is believed to account for the powerful and selective effect of opiates on spinal nociceptive processing. A variety of opiates delivered spinally (intrathecally or epidurally) can induce powerful analgesia that is reversed by low doses of systematic naloxone.

\section{Peripheral actions.}

Direct application of high concentrations of opiates to a peripheral nerve can in fact, produce a local anaesthetic-like action, but this effect is not reversed by naloxone and is believed to reflect a "nonspecific" action. Conversely, at peripheral sites under conditions of inflammation where there is an increased sensitivity leading to an exaggerated pain response, direct injection of opiates produces a local action than can exert a normalizing effect on exaggerated thresholds. Whether the effects are uniquely on the peripheral afferent terminal or whether the opiate acts on inflammatory cells that release products that sensitize the nerve terminal, or both, is not known [1].

\section{Absorption, distribution, metabolism and excretion of opioids}

\section{Absorption.}

In general, the opioids are modestly well absorbed from the gastrointestinal tract; absorption through the rectal mucosa is adequate, and a few agents (e.g., morphine and hydromorphone) are available in suppositories. The more lipophilic opioids are absorbed readily through the nasal or buccal mucosa. Opioids, particularly morphine, have been widely used for spinal delivery to produce analgesia though a spinal action. With most opioids, including morphine, the effect of a given dose is less after oral than after parenteral administration because of variable but significant first-pass metabolism in the liver. For example, the bioavailability of oral preparations of morphine is only $25 \%$. If adjustment is made for variability of first-pass metabolism and clearance, adequate relief of pain can be achieved with oral administration of morphine. When morphine and most opioids are given intravenously they act promptly. Compared to more lipid-soluble opioids such as codeine, heroin, and methadone, morphine cross the blood-brain-barrier at considerably lower rate.

\section{Distribution and metabolism.}

About one-third of morphine in the plasma is protein bound after a therapeutic dose. Morphine itself does not persist in tissues, and 24 hours after the last dose, tissue concentrations are low. The major pathway for the metabolism of morphine is conjugation with glucuronic acid. The two major metabolites formed are morphine-6-glucuronide and morphine-3glucuronide. Small amounts of morphine-3,6-glucuronide also may be formed. Although the 3- and 6-glucuronudes are polar, both still can cross the blood-brain-barrier to exert significant clinical effects. Morphine-6glucuronide has pharmacological actions indistinguishable from those of morphine. Morphine-6-glucuronide given systemically is approximately twice as potent as morphine in animal models and in humans. With chronic administration, the 6-glucuronide accounts for a significant portion of morphine's analgesic action. Indeed, with chronic oral dosing, thee blood levels of morphine-6-glucuronide typically exceed those of morphine. Given its greater MOR potency and its higher concentration, morphine-6-glucuronide may be responsible for most of morphine's analgesic activity in patients receiving chronic oral morphine. Morphine6-glucuronide is excreted by the kidney. N-demethylation of morphine to normorphine is a minor metabolic pathway in humans. Excretion. Morphine is eliminated by glomerular filtration, primarily as morphine3 -glucuronide; $90 \%$ of the total excretion takes place during the first day.
Vere little morphine is excreted unchanged. Extrahepatic circulation of morphine and its glucuronides occur, which accounts for the presence of small amounts of morphine in faeces and urine for several days after the last dose [1]. Morphine is the best-studied opiate analgesic used in the neonatal population [2]. Morphine is an important agent for analgesia and sedation. It is used in the treatment of opioid dependence and neonatal abstinence syndrome. Morphine is incompatible with azithromycin, cefepime, micafungin, phenobarbital and phenytoin [3].

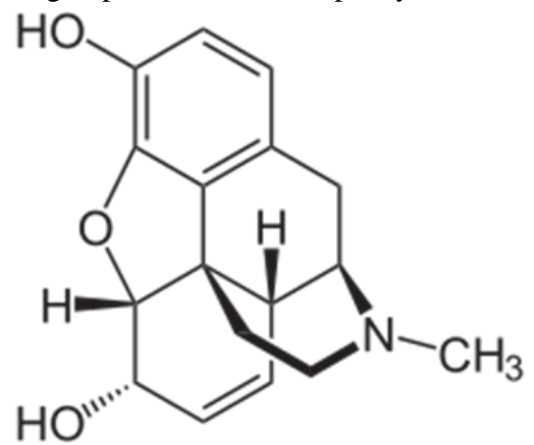

Morphine molecular structure (molecular weight $=285.34$ grams $/$ mole $)$

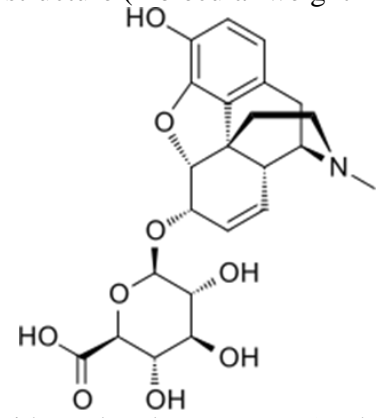

Morphine-6-glucuronide molecular structure (molecular weight $=461.46$ grams/mole)

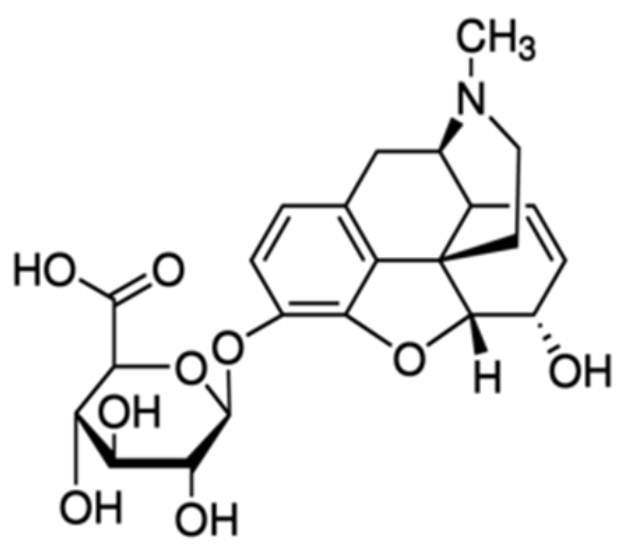

Morphine-3- $\beta$-D-glucuronide molecular structure $($ molecular weight $=$ 461.46 grams/mole)

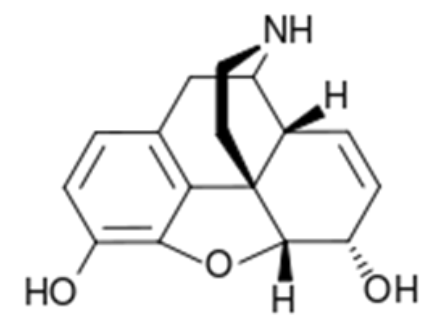

Normorphine molecular structure (molecular weight $=271.311$ grams/mole) 


\section{Literature search}

The literature search was performed electronically using PubMed database as search engine and the following key words were used: "morphine dosing infants, children", morphine efficacy, safety infants, children", "morphine effects infants, children", "morphine adverseeffects infants, children", "morphine pharmacokinetics infants, children", "morphine metabolism", "morphine drug interaction", "morphine treatment infants, children", "morphine transport into human brain", "morphine placental transfer", and "morphine breast-milk". In addition, the books: The Pharmacological Basis of Therapeutics [1], Neonatal Formulary [2], NEOFAX ${ }^{\circledR}$ by Young and Mangum [3], and The British National Formulary for Children [4] are consulted.

\section{Results}

\section{Administration schedules of morphine to infants and children}

Administration to infants [2]

\section{Neonatal opioid withdrawal:}

Local guidelines may vary; one approach is to monitor using appropriate withdrawal tool (e.g., modified Finnegan's score every 4 hours). If morphine is required, begin by giving $40 \mu \mathrm{g} / \mathrm{kg}$ by mouth 6 times-daily.

\section{Severe or sustained pain:}

Provide ventilator support; give a loading dos of $200 \mu \mathrm{g} / \mathrm{kg}$, and then a maintenance infusion of $20 \mu \mathrm{g} / \mathrm{kg}$ per hour. While this will usually control even severe pain in the first two months of life, providing a plasma morphine level of 120 to $160 \mu \mathrm{g} / \mathrm{ml}$, treatment has to be individualized.

\section{Sedation while ventilated:}

Infants given both a loading dose of $100 \mu \mathrm{g} / \mathrm{kg}$ and a maintenance infusion of $10 \mu \mathrm{g} / \mathrm{kg}$ per hour.

\section{Short-tern pain relief:}

Give $100 \mu \mathrm{g} / \mathrm{kg}$ by subcutaneous or, preferably, by intravenous injection. Avoid intramuscular injection which is pain in itself. Twice this dose is needed if given by mouth. Rapid intravenous administration does not cause hypotension but may cause respiratory depression. A further 50 $\mu \mathrm{g} / \mathrm{kg}$ dose can usually be given after 6 hours without making ventilator support necessary.

Administration to children [4]

\section{Treatment of pain by subcutaneous injection}

Children aged 1 to 5 months. Give initially 100 to $200 \mu \mathrm{g} / \mathrm{kg} 4$ timesdaily, and then adjust the dose according to the response.

Children aged 6 months to 1 year. Give initially 100 to $200 \mu \mathrm{g} / \mathrm{kg} 6$ times-daily, and then adjust the dose according to the response.

Children aged 2 to 12 years. Give initially $200 \mu \mathrm{g} / \mathrm{kg} 6$ times-daily, and then adjust the dose according to the response.

Children aged 12 to 17 years. Give initially 2.5 to $10 \mathrm{mg} 6$ times-daily, and then adjust the dose according to the response.

Treatment of pain by intravenous injection

Children aged 1 to 5 months. Give: $100 \mu \mathrm{g} / \mathrm{kg} 4$ times-daily, and then adjust the dose according to the response, the dose should be administered over at least $5 \mathrm{~min}$, alternatively (by intravenous injection) give initially $50 \mu \mathrm{g} / \mathrm{kg}$, the dose should be administered over at least $5 \mathrm{~min}$, followed by a continuous intravenous infusion of 10 to $30 \mu \mathrm{g} / \mathrm{kg}$ per hour, and then adjust the dose according to the response.
Children aged 6 months to 11 years. Give: $100 \mu \mathrm{g} / \mathrm{kg} 6$ times-daily, and then adjust the dose according to the response, the dose should be administered over at least $5 \mathrm{~min}$, alternatively by a continuous intravenous infusion give initially $100 \mu \mathrm{g} / \mathrm{kg}$ and the dose should be administered over at least $5 \mathrm{~min}$, followed by a continuous intravenous infusion of 20 to 30 $\mu \mathrm{g} / \mathrm{kg}$ per hour, and then adjust the dose according to the response.

Children aged 12 to 17 years. Give: $5 \mathrm{mg} 6$ times-daily, adjust the dose according to the response, the dose should be administered over at least 5 $\mathrm{min}$, alternatively by an intravenous injection give initially $5 \mathrm{mg}$, the dose should be administered over at least $5 \mathrm{~min}$, followed by a continuous intravenous infusion of 20 to $30 \mu \mathrm{g} / \mathrm{kg}$ per hour, and then adjust the dose according to the response.

\section{Treatment of pain by moth or by rectum}

Children aged 1 to 2 months. Give initially 50 to $100 \mu \mathrm{g} / \mathrm{kg} 6$ timesdaily, and then adjust the dose according to the response.

Children aged 3 to 5 months. Give: 100 to $150 \mu \mathrm{g} / \mathrm{kg} 6$ times-daily, and then adjust the dose according to the response.

Children aged 6 to 11 months. Give: $200 \mu \mathrm{g} / \mathrm{kg} 6$ times-daily, and then adjust the dose according to the response.

Children aged 1 year. Give initially 200 to $300 \mu \mathrm{g} / \mathrm{kg} 6$ times-daily, and then adjust the dose according to the response.

Children aged 2 to 11 years. Give initially 200 to $300 \mu \mathrm{g} / \mathrm{kg} 6$ timesdaily (maximum per dose $=10 \mathrm{mg}$ ), and then adjust the dose according to the response.

Children aged 12 to 17 years. Give initially 5 to $10 \mathrm{mg} 6$ times-daily, and then adjust the dose according to the response.

Treatment of pain by continuous subcutaneous infusion

Children aged 1 to 2 months. Give: $10 \mu \mathrm{g} / \mathrm{kg}$ per hour, and then adjust the dose according to the response.

Children aged 3 months to 17 years. Give: $20 \mu \mathrm{g} / \mathrm{kg}$ per hour, and then adjust the dose according to the response.

\section{Efficacy and safety of morphine in infants and children}

Oral morphine given at a dose of $100 \mu \mathrm{g} / \mathrm{kg}$ to non-ventilated premature infants effectively and safely treats pain [5]. Combination of morphine with gabapentin provides better analgesia than morphine alone and this combination is safe in children [6]. Nebulized morphine, or a bolus of 10 $\mathrm{mg}$, has similarly efficacy and safe than intravenous morphine in children with severe posttraumatic pain [7]. No significant difference in analgesic effect is observed between oral morphine and oral ibuprofen in children [8]. Morphine is efficacy and safe in treating pain in newborns, infants, and children [9]. Caudal anaesthesia supplemented with low dose of morphine provides a long duration of analgesia without significant adverse-effects in children undergoing renal surgery [10]. Caudal morphine provides 8 to 24 hours analgesia in children without causing significant adverse-effects than caudal bupivacaine or intravenous morphine [11]. In children, the duration of pain relief is significantly longer using morphine (range, 610 to $2,195 \mathrm{~min}$ ) than using bupivacaine (range, 245 to $515 \mathrm{~min}$ ) [12].

\section{Effects of morphine in infants and children}

Newborns, with neonatal abstinence syndrome, treated with morphine have significantly higher scores in cognitive and gross motor domains compared to infants treated with methadone [13]. Medication of preterm infants with morphine is associated with prolonged amplitude-integrated electroencephalogram depression independent of blood pressure changes [14]. Newborns and young infants have the same respiratory response to morphine infusions as older infants and children at the same blood level 
[15]. When morphine is administered to patients, the analgesic effect is mainly caused by morphine-6-glucuronide instead of morphine itself [16]. Morphine provides enhanced cardio-protection against ischemia/reperfusion injury in children undergoing corrections of Tetralogy of Fallot [17].

\section{Adverse-effects caused by morphine in infants and children [4]}

\section{Common or very common adverse-effects}

\section{With oral use:}

Appetite decreased, asthenic conditions, gastrointestinal discomfort, insomnia, and neuromuscular dysfunction.

\section{Uncommon adverse-effects}

With oral use:

Agitation, bronchospasm, mood altered, myoclonus, peripheral oedema, pulmonary oedema, seizures, sensational abnormal, syncope, and taste altered.

\section{Adverse-effects whose frequency is not known}

With oral use:

Amenorrhoea, biliary pain, cough decreased, hyperalgesia, hypertension, pancreatitis exacerbated, sexual dysfunction, thinking abnormal and ureteral spams.

\section{With parenteral use:}

Alertness decreased, bile ductus disorders, mood altered, myoclonus, sexual dysfunction, ureteral spasm, urinary disorders, and vision disorders.

\section{Pharmacokinetics of morphine in preterm newborns}

Scott et al. [18] 48 preterm newborns were stratified according to the postconceptional age and morphine infusions were initiated at doses of 20 to $30 \mu \mathrm{g} / \mathrm{kg}$ per hour preceded by a bolus infusion of $50 \mu \mathrm{g} / \mathrm{kg}$.

\begin{tabular}{|l|l|l|l|l|l|}
\hline PCA group & PCA age (week) & Gestational age (week) & Postnatal age (week) & Body-weight (grams) & Sex (M:F) \\
\hline A $(\mathrm{N}=10)$ & $26.8+0.7$ & $26.6+0.7$ & $1.1+0.3$ & $1,083+174$ & $8: 2$ \\
\hline B $(\mathrm{N}=16)$ & $29.8+1.4$ & $29.5+1.3$ & $1.3+0.6$ & $1,438+239$ & $13: 3$ \\
\hline $\mathrm{C}(\mathrm{N}=15)$ & $33.1+1.6$ & $32.5+1.6$ & $6.1+9.1$ & $2,142+412$ & $8: 7$ \\
\hline $\mathrm{D}(\mathrm{N}=7)$ & $37.8+1.5$ & $35.4+4.8$ & $16.4+31.6$ & $3,323+464$ & $4: 3$ \\
\hline
\end{tabular}

Table 1. Demographic characteristics of preterm newborns included in the study. Figures are the mean+SD, by Scott et al. [18].

\begin{tabular}{|c|c|c|c|c|c|c|c|}
\hline Group & $\begin{array}{l}\text { Ko (all) } \\
(\mu \mathrm{g} / \mathrm{kg} / \mathrm{h})\end{array}$ & $\begin{array}{l}\text { Ko (Css) } \\
(\mu \mathrm{g} / \mathrm{kg} / \mathrm{h})\end{array}$ & Css (ng/ml) & $\begin{array}{l}\text { Total body } \\
\text { clearance } \\
\text { (ml } / \mathrm{kg} / \mathrm{min})\end{array}$ & $\operatorname{Ke}\left(h^{-1}\right)$ & $\begin{array}{l}\text { Elimination } \\
\text { half-life (h) }\end{array}$ & $\begin{array}{l}\text { Distribution } \\
\text { volume } \\
(\mathrm{L} / \mathrm{kg})\end{array}$ \\
\hline $\mathrm{A}(\mathrm{N}=10)$ & $24.0+9.7$ & $24.4+10.1$ & $207+99.4^{*}$ & $2.27+1.07 * *$ & $0.066+0.046$ & $13.5+8.1$ & $2.2+0.67$ \\
\hline $\mathrm{B}(\mathrm{N}=16)$ & $22.4+5.9$ & $22.9+6.4$ & $120+34.6$ & $3.21+1.57$ & $0.081+0.027$ & $9.2+2.2$ & $2.44+1.01$ \\
\hline $\mathrm{C}(\mathrm{N}=14)$ & $24.1+5.3$ & $24.5+5.4$ & $108+54.9$ & $4.51+1.97$ & $0.144+0.049$ & $7.0+2.3$ & $2.4+0.69$ \\
\hline $\mathrm{D}(\mathrm{N}=4)$ & $30.0+20.2$ & $33.3+23.1$ & $74.2+46.0$ & $7.80+2.67 \S$ & $0.120+0.077$ & $7.7+4.8$ & $3.83+3.32$ \\
\hline
\end{tabular}

Ko (all) $=$ morphine infusion rate for all subjects completing the study. Ko $(\mathrm{Css})=$ morphine infusion rate for subjects reaching Css. Css $=$ morphine concentration at the steady-state. $* \mathrm{P}$-value $=0.02$; group $\mathrm{A}$ versus groups $\mathrm{B}, \mathrm{C}$, and $\mathrm{D} .{ }^{*} * \mathrm{P}$-value $=0.023$; group $\mathrm{A}$ versus groups $\mathrm{C}$ and $\mathrm{D}$. ${ }^{\S} \mathrm{P}$-value $<$ 0.001 ; group D versus groups $\mathrm{A}, \mathrm{B}$, and $\mathrm{C}$.

Table 2. Pharmacokinetic parameters of morphine which are obtained in 44 preterm newborns. Figures are the mean+SD, by Scott et al. [18].

This table shows that the concentration of morphine at the steady-state decreases according to the subject maturation, and the total body clearance increases according to the subject maturation. Morphine is cleared from the body by metabolism and renal excretion and both elimination pathways increase with the infant maturation.

Pharmacokinetics of morphine and its metabolites in newborns, infants, and young children

\begin{tabular}{|l|l|l|l|l|l|l|l|}
\hline Age (days) & $\begin{array}{l}\text { DV } \\
(\mathrm{L} / 70 \mathrm{~kg})\end{array}$ & $\begin{array}{l}\text { CL 2M6G } \\
(\mathrm{L} / \mathrm{h} / 70 \mathrm{~kg})\end{array}$ & $\begin{array}{l}\text { CL 2M3G } \\
(\mathrm{L} / \mathrm{h} / 70 \mathrm{~kg})\end{array}$ & $\begin{array}{l}\text { CLM3G } \\
(\mathrm{L} / \mathrm{h} / 70 \mathrm{~kg})\end{array}$ & $\begin{array}{l}\text { CLM6G } \\
(\mathrm{L} / \mathrm{h} / 70 \mathrm{~kg})\end{array}$ & $\begin{array}{l}\text { CLEX } \\
(\mathrm{L} / \mathrm{h} / 70 \mathrm{~kg})\end{array}$ & $\begin{array}{l}\text { CLT } \\
(\mathrm{L} / \mathrm{h} / 70 \mathrm{~kg})\end{array}$ \\
\hline 0 & 84 & 0.61 & 10.8 & 3.0 & 0.98 & 3.12 & 14.5 \\
\hline 7 & 92 & 0.76 & 13.5 & 3.6 & 1.2 & 3.12 & 17.4 \\
\hline 30 & 112 & 1.34 & 22.0 & 5.1 & 1.7 & 3.12 & 26.3 \\
\hline 90 & 131 & 2.14 & 37.8 & 8.5 & 2.8 & 3.12 & 43.1 \\
\hline 180 & 136 & 2.90 & 51.3 & 11.9 & 4.0 & 3.12 & 57.3 \\
\hline 365 & 136 & 3.50 & 61.2 & 15.4 & 5.1 & 3.12 & 67.8 \\
\hline 1,000 & 136 & 3.63 & 64.3 & 17.3 & 5.8 & 3.12 & 71.1 \\
\hline
\end{tabular}

$\mathrm{DV}=$ distribution volume. CL2M6G = formation clearance to morphine-6-glucuronide. CL2M3G = formation clearance to morphine-3-glucuronide. CLM3G = elimination clearance of morphine-3-glucuronide. $C L M 6 G=$ elimination clearance of morphine-6-glucuronide. CLEX = morphine clearance by other routes. CLT base $=$ Total body clearance of morphine.

Table 3. Pharmacokinetics of morphine and its metabolites which are obtained in 184 subjects aged 0 to 3 years. The estimates are standardized to a $70 \mathrm{~kg}$ person and are the median, by Bouwmeester et al. [19]. 
This table shows that the elimination clearance of morphine-3glucoronide, morphine-6-glucuronide, and the total body clearance of morphine increases with infant maturation and child development.

\section{Metabolism of morphine}

\begin{tabular}{|l|l|l|l|l|}
\hline & Plasma concentration $(\mathrm{ng} / \mathrm{ml})$ & Morphine-6-glucuronide & Plasma M3G/morphine \\
\hline Value & Morphine & Morphine-3-glucuronide & Morl & 15.2 \\
\hline Minimum & 9 & 312 & ND & 29.3 \\
\hline Maximum & 132 & 3,863 & 84 & 23.9 \\
\hline Mean & 34 & 837 & 43 & +6.4 \\
\hline SD & +42 & $+1,189$ & +34 & \\
\hline
\end{tabular}

Table 4. Concentrations of morphine, morphine-3-glucuronide, and morphine-6-glucuronide which are measured in the plasma of 9 children. Figures are the minimum, maximum, mean, and $+S D$, by Choonara et al. [20].

$\mathrm{ND}=$ not detectable. $\mathrm{M} 3 \mathrm{G}=$ morphine-3-glucuronide .

This table shows that the plasma concentration of morphine-3-glucuronide is higher than those of morphine and morphine-6-glucuronide.

\begin{tabular}{|l|l|l|l|l|}
\hline \multicolumn{2}{|l|}{ Plasma concentration $(\mathrm{ng} / \mathrm{ml})$} & Morphine-6-glucuronide & Plasma M3G/morphine \\
\hline Value & Morphine & Morphine-3-glucuronide & ND & 0.9 \\
\hline Minimum & 26 & 123 & ND & 14.3 \\
\hline Maximum & 210 & 548 & --- & 5.0 \\
\hline Mean & 113 & 339 & --- & +4.6 \\
\hline +SD & +70 & +136 & & \\
\hline
\end{tabular}

Table 5. Concentrations of morphine, morphine-3-glucuronide, and morphine-6-glucuronide which are measured in the plasma of 9 infants. Figures are the minimum, maximum, mean, and $+S D$, by Choonara et al. [20].

$\mathrm{ND}=$ not detectable $\mathrm{M} 3 \mathrm{G}=$ morphine-3-glucuronide .

This table shows that the plasma concentration of morphine-3glucuronide is higher than that of morphine and morphine-6-glucorinide is not detectable. In addition, the plasma concentration of morphine is higher in infants than children and the plasma concentration of morphine3 -glucuronide is lower in infants than.

In adult patients, morphine-6-glucuronide and morphine-3-glucuronide are present in abundance after chronic oral morphine administration and the plasma AUC of morphine-3-glucuronide exceeds that of morphine-6glucuronide [21]. The ratio of hydromorphone to morphine plasma concentration ranges from 0.015 to 0.024 , thus hydromorphone is a minor metabolite of morphine in humans [22]. Plasma morphine concentrations are correlated with the volume of liver $(\mathrm{P}$-value $<0.02)$. Whereas the plasma concentrations of morphine-6-glucuronide and morphine-3glucuronide did not differ between patients who underwent liver resection compared to a control group of patients who underwent colon resection [23]. Morphine is glucuronidated in traces by human skin indicating that the biotransformation in the skin is negligible when morphine is applied to skin [24].

\section{Interaction of morphine with drugs}

The interaction between morphine and phenelzine is limited [25]. Morphine significantly decreases the peak plasma concentration of prasugrel [26]. Morphine co-administered with acetylsalicylic acid increase the acetylsalicylic acid exposure by $20 \%$ [27]. Co-administration of morphine with prasugrel or ticagrelor, inhibitors of P2Y12, decreases their efficacy in platelet inhibition [28]. The combination of morphine with tramadol produces opioid sparing effect and synergism [29]. There is a potentiation of morphine analgesia when morphine is co-administered with lithium [30]. Morphine co-administered with ticagrelor decreases ticagrelor plasma concentrations [31]. Gabapentin and morphine combination produces better analgesia than morphine alone [32]. In patients with ST-segment-elevation myocardial infarction, morphine use is associated with a delayed onset of action of the oral antiplatelet agents [33].

\section{Treatment of infants and children with morphine}

Morphine is able to control withdrawal symptoms in infants exposed to opioids in utero [34]. Newborns, with neonatal abstinence syndrome, were treated with morphine which significantly produces higher scores in cognitive and gross motor domains compared to infants treated with methadone [35]. Neonatal abstinence syndrome treatment with morphine is associated with better outcomes in infants compared to methadone treatment [36]. Methadone has a shorter length of neonatal withdrawal treatment compared to morphine [37]. There are no significant differences in the duration of treatment, duration of hospital stay, and the requirement for adjunctive treatment between newborns with neonatal abstinence syndrome who received morphine sulfate and newborns who received phenobarbital [38]. Clonidine is a favourable alternative to morphine for neonatal abstinence syndrome [39]. Chlorpromazine shorts the duration of neonatal abstinence syndrome more effectively than morphine hydrochloride [40]. Morphine has a better analgesic effect in children than control children who did not receive morphine [41]. Patients with Pglycoprotein $^{+}$tumours require a higher dose of morphine to achieve an analgesic effect [42]. Inhaled morphine is associated with a beneficial effect on dyspnoea [43].

\section{Transport of morphine into the human brain}

Morphine-6-glucuronide and Morphine-3-glucuronide are both highly hydrophilic, but only morphine-6-glucuronide penetrates the blood-brainbarrier. Morphine-6-glucuronide produces higher analgesic effect than the parent drug and morphine-3-glucuronide [44]. In patients who received $10 \mathrm{mg}$ of morphine, the elimination half-life and Tmax of morphine are longer in the brain than in plasma and morphine crosses the blood-brain-barrier by active efflux [45].

\section{Transfer of morphine across the human placenta}

Twenty-five healthy women in labour received morphine intrathecally at a dose of 1 to $1.75 \mathrm{mg}$, the maternal plasma concentration of morphine is $6 \mathrm{ng} / \mathrm{ml}$ or less and the mean umbilical arterial plasma concentration of morphine is $0.8 \mathrm{ng} / \mathrm{ml}$ [46]. Morphine was intravenously infused and at 
steady-state the maternal to foetal free drug concentration ratio is 7.6+0.6 [47]. Term human placental cotyledons were perfused in-vitro. The placenta was perfused with $50 \mathrm{ng} / \mathrm{ml}$ of morphine and the maternal-tofoetal morphine transfer rate is $0.73+0.44 \mathrm{ng} / \mathrm{ml} / \mathrm{min}$. The final morphine concentrations is $9.78+6.17 \mathrm{ng} / \mathrm{ml}$ (maternal compartment) and $3.43+2.14$ $\mathrm{ng} / \mathrm{ml}$ (foetal compartment) thus morphine does not equilibrated between the maternal and foetal compartment [48].

\section{Migration of morphine into the breast-milk}

Morphine concentration in maternal serum is $4 \mathrm{ng} / \mathrm{ml}$ while the concentration in the breast-milk varies in three samples collected within 2 hours and are 10, 100, $12 \mathrm{ng} / \mathrm{ml}$ [49]. The milk-to-plasma ratio is $2.45+0.8[50]$.

\section{Discussion}

Morphine is the best-studied opiate analgesic in adult and paediatric patients and the analgesic effect is supraspinal, spinal, and peripheral. Morphine is used to treat pain; it is an important agent for analgesia and sedation, is used in the treatment of opioid dependence, and for treatment of neonatal abstinence syndrome. Morphine may be administered by intravenous or subcutaneous injection, orally, by rectum, by continuous subcutaneous infusion or by intranasal or buccal application. Following oral administration, the bioavailability is modest whereas after rectal administration and intranasal and buccal application the bioavailability is good [1]. In infants, morphine may be administered to control severe or sustained pain, for sedation in ventilated infants, and for short-term relief pain and the treatment consists in an intravenous loading dose followed by a maintenance infusion [2]. In children, morphine is administered by subcutaneous or intramuscular injection, by rectum, by continuous subcutaneous infusion, or orally and the dose of morphine varies according to the child age. Morphine has been found efficacy and safe in infants and children [5-12]. Oral morphine given, at a dose of $100 \mu \mathrm{g} / \mathrm{kg}$, effectively and safely treats pain in premature infants [5], and the combination of morphine with gabapentin provides better analgesia than morphine alone in children [6]. Nebulized morphine has similar efficacy than intravenous morphine in children with severe posttraumatic pain [7], and oral morphine and oral ibuprofen have similar analgesic efficacy [8]. Morphine effectively and safely treats pain in newborns, infants and children [9]. In children undergoing renal surgery, caudal anaesthesia supplemented with low dose of morphine provides a long analgesia without inducing adverse-effects [10] and caudal morphine provides analgesia in children compared to caudal bupivacaine or intravenous morphine [11]. In children, the pain relief is longer using morphine than bupivacaine [12]. The effects of morphine have been reported in infants and children [13-17]. The treatment of neonatal abstinence syndrome in newborns is more efficacious with morphine than with methadone [13], and medication of preterm infants with morphine is associated with prolonged amplitude-integrated electroencephalogram depression [14]. Newborns and young infants have similar respiratory response to morphine infusion as older infants and children at the same blood level [15]. The analgesic effect caused by morphine is mainly due to morphine6-glucuronide [16], and morphine provides enhanced cardioprotective against ischemic/reperfusion injury undergoing corrections of Tetralogy of Fallot [17]. The pharmacokinetics of morphine have been studied in preterm newborns [18] and in newborns, infants, and children [19]. In preterm newborns, morphine elimination half-life ranges from 7.7 to 13.5 hours and decreases with infant maturation and the total body clearance ranges from 2.27 to $7.80 \mathrm{ml} / \mathrm{kg} / \mathrm{min}$ and increases with infant maturation [18]. In newborns, infants, and children, the total body clearance of morphine ranges from 14.5 to $71.1 \mathrm{~L} / \mathrm{h} / 70 \mathrm{~kg}$, and increases with infant maturation and child development. The elimination clearance of morphine-3-glucuronide ranges from 3.0 to $17.3 \mathrm{~L} / \mathrm{h} / 70 \mathrm{~kg}$, and that of morphine-6-glucuronide ranges from 0.98 to $5.8 \mathrm{~L} / \mathrm{h} / 70 \mathrm{~kg}$ and both increase with infant maturation and child development [19]. Morphine is cleared from the body by renal route and by metabolism and both elimination pathways increase with infant maturation and child development. The metabolism of morphine has been studied in infants and children [20] and in adult patients [21-24]. In infants, the plasma concentrations of morphine and morphine-3-glucuronide are 113 and 339 $\mathrm{ng} / \mathrm{ml}$, respectively, and that of morphine-6-glucuronine is not detectable. In children, the plasma concentrations of morphine, morphine-3glucuronide, and morphine-6-glucuronide are 34, 837, and $43 \mathrm{ng} / \mathrm{ml}$, respectively [20]. These results indicate that morphine plasma concentration is lower in children than in infants because of a more extensive metabolism of morphine in children. Consequently, the plasma concentration of morphine-3-glucuronide is higher in children than in infants and morphine-6-glucuronide is not detectable in the plasma of infants. In children, the plasma concentration of morphine-3-glucuronide is higher than that of morphine-6-glucuronide and consisting results have been observed in adult patients [21]. Hydromorphone is formed following morphine administration to adult patients and hydromorphone is a minor metabolite of morphine. In adult patients, the plasma concentration of morphine is correlated with the liver volume [22, 23] and the plasma concentrations of morphine-6-glucuronide and morphine-3-glucuronode do not vary in patients undergoing liver resection compared to patients undergoing colon resection [23]. Human skin poorly metabolizes morphine [24]. Morphine interacts with drugs [25-33]. The interaction of morphine with phenelzine is limited [25] whereas morphine decreases the peak concentration of prasugrel [26], morphine increases the acetylsalicylic acid exposure [27], and the co-administration of morphine with prasugrel or ticagrelor, inhibitors of P2Y12, decrease their efficacy in platelet inhibition [28]. The combination of morphine with tramadol produces both opioid sparing effect and synergism [29], and the analgesic effect of morphine is potentiated by the co-administration of lithium [30]. Morphine decreases the ticagrelor plasma concentration [30], the combination of gabapentin with morphine produces better anaesthesia even when administered at low dose [32], and morphine is associated with a delayed onset of action of oral antiplatelet agents [33]. The treatment of infants and children with morphine has been extensively studied [34-43]. Morphine controls the withdrawal symptoms in infants exposed to opioids in utero [35], morphine is more active than methadone in controlling the neonatal abstinence syndrome in newborns [36], methadone is less effective than morphine in controlling neonatal withdrawal [37], morphine and phenobarbital have similar efficacy in the treatment of newborns with neonatal abstinence syndrome [38], and clonidine is a preferable alternative to morphine in the treatment of neonatal abstinence syndrome [39]. Chlorpromazine is more effective than morphine in shortening the duration of neonatal abstinence syndrome [40], and morphine has a better analgesic effect than placebo in children [41]. Patients with P-glycoprotein ${ }^{+}$tumours require higher dose of morphine to achieve the analgesic effect [42]. Inhaled morphine produces a beneficial effect on dyspnoea [43]. The transport of morphine and its metabolites has been studied in two occasions [44, 45]. Morphine and morphine-6glucuronide cross the blood-brain-barrier whereas morphine-3glucuronide is not transported into the human brain [44]. The morphine elimination half-life and Tmax are longer in brain than in plasma and morphine crosses the blood-brain-barrier by active efflux [45]. The transfer of morphine across the human placenta has been studied in-vivo $[46,47]$ and in-vitro using the placenta perfusion [48]. Morphine reaches lower concentration in neonatal plasma than in maternal plasma $[46,47]$ and morphine concentration in the perusing medium remains lower in the foetal than in maternal compartment [48]. The migration of morphine into the breast-milk has been investigated in two occasions and morphine reaches higher concentrations in the breast-milk than in maternal plasma $[49,50]$.

In conclusion, morphine is an important agent for treating analgesia and sedation and it is used in the treatment of opioid dependence and neonatal abstinence syndrome. Morphine may be administered by intravenous or 
subcutaneous injection, orally, by rectum, by continuous subcutaneous infusion or by intranasal or buccal application. Following oral administration, the bioavailability is modest whereas after rectal administration and intranasal or buccal application the bioavailability is good. In infants, intravenous morphine is used to treat severe, sustained pain, sedation, and for short-term pain relief. In children, the treatment of pain with morphine is obtained by subacute or intravenous injection, by mouth or by rectum administration, or by continuous subcutaneous infusion and the morphine dose varies according to the child age. Morphine has been found efficacy and safe in infants and children but may induce adverse-effects. The effects and the treatment with morphine have been extensively studied in infants and children. The pharmacokinetics of morphine have been studied in newborns and in newborns, infants and children. Morphine elimination half-life decreases and the total body clearance increases with infant maturation and child development. Morphine is metabolized; the main metabolites are morphine-3-glucurinide and morphine-6-glucuronide and the plasma concentration of the former is higher than that of the latter. Morphine is transported into the human brain and the elimination half-life of morphine is longer in brain than in plasma. Morphine poorly crosses the placenta whereas the breast-milk concentrations of morphine are higher than those in plasma. The aim of this study is to review the clinical pharmacology of morphine in infants and children.

\section{Conflict of interests}

The authors declare no conflicts of financial interest in any product or service mentioned in the manuscript, including grants, equipment, medications, employments, gifts, and honoraria.

This article is a review and drugs have not been administered to men or animals.

\section{Acknowledgments}

The author thanks Dr. Patrizia Ciucci and Dr. Francesco Varricchio, of the Medical Library of the University of Pisa, for retrieving the scientific literature.

\section{References}

1. Yaksh T, Wallace M (2018) . "Opioids, Analgesia, and Pan Management”. In The Goodman \& Gilman's. The Pharmacological Basis of the Therapeutics, Brunton Hilaldandan LL, Knollmann BC, Eds. Mc Graw Hill, $13^{\text {th }}$ Edition, USA, New York, pp. 355-386.

2. Neonatal Formulary (2020). "Morphine". Oxford University Press. $8^{\text {th }}$ Edition, Great Clarendon Street, Oxford, OX2, 6DP, UK, pp: 530-533.

3. Young TE, Mangum B (2010). NEOFAX ${ }^{\circledR}$. "Morphine". Thomas Reuters Clinical Editorial Staff, 23 ${ }^{\text {rd }}$ Edition, Montvale, USA, , pp: 224-225.

4. The British national formulary for children. "Morphine". Macmillan, $78^{\text {th }}$ Edition, Hampshire International Business Park, Hampshire, Lime Three Way, Basingstoke, Hampshire, UK, 2019-2020, pp: 290-294.

5. 5. Hartley C, Moultrie F, Hoskin A, Green G, Monk V, Bell JL, et al (2018). 1. Analgesic efficacy and safety of morphine in the Procedural Pain in Premature Infants (Poppi) study: randomised placebo-controlled trial. Lancet.; 32(10164): 2595-2605.

6. de Leeuw TG, Mangiarini L, Lundin R, Kaguelidou F, van der Zanden T, Della Pasqua O, et al (2019). Gabapentin as add-on to morphine for severe neuropathic or mixed pain in children from age 3 months to 18 years - evaluation of the safety, pharmacokinetics, and efficacy of a new gabapentin liquid formulation: study protocol for a randomized controlled trial. Trials.; 20(1): 49. doi: 10.1186.

7. Grissa MH, Boubaker H, Zorgati A, Beltaïef K, Zhani W, Msolli MA et al (2015). Efficacy and safety of nebulized morphine given at 2 different doses compared to IV titrated morphine in trauma pain. Am J Emerg Med; 33(11): 15571561.

8. Poonai N, Bhullar G, Lin K, Papini A, Mainprize D, Howard $\mathrm{J}$, et al (2014). Oral administration of morphine versus ibuprofen to manage postfracture pain in children: a randomized trial. CMAJ. 186(18): 1358-1363.

9. Kart T, Christrup LL, Rasmussen M (1997). Recommended use of morphine in neonates, infants and children based on a literature review: Part 2-Clinical use. Paediatr Anaesth.; 7(2): 93-101.

10. Chertin B, Zeldin A, Kocherov S, Ioscovich A, Ostrovsky IA, Gozal Y (2016). Use of Caudal Analgesia Supplemented with Low Dose of Morphine in Children Who Undergo Renal Surgery. Curr Urol.; 9(3): 132-137.

11. Krane EJ, Jacobson LE, Lynn AM, Parrot C, Tyler DC (1987). Caudal morphine for postoperative analgesia in children: a comparison with caudal bupivacaine and intravenous morphine. Anesth Analg.; 66(7): 647-653.

12. Jensen BH (1981). Caudal block for post-operative pain relief in children after genital operations. A comparison between bupivacaine and morphine. Acta Anaesthesiol Scand.; 25(5): 373-375.

13. Norman E, Wikström S, Rosén I, Fellman V, HellströmWestas L (2013). Premedication for intubation with morphine causes prolonged depression of electrocortical background activity in preterm infants. Pediatr Res.; 73(1): 87-94.

14. de Graaf J, van Lingen RA, Simons SH, Anand KJS, Duivenvoorden HJ, Weisglas-Kuperus N, et al (2011). Longterm effects of routine morphine infusion in mechanically ventilated neonates on children's functioning: five-year follow-up of a randomized controlled trial. Pain.; 152(6): 1391-1397.

15. Lynn AM, Nespeca MK, Opheim KE, Slattery JT (1993). Respiratory effects of intravenous morphine infusions in neonates, infants, and children after cardiac surgery. Anesth Analg.; 77(4): 695-701

16. Klimas R, Mikus G (2014). Morphine-6-glucuronide is responsible for the analgesic effect after morphine administration: a quantitative review of morphine, morphine6-glucuronide, and morphine-3-glucuronide. Br J Anaesth.; 113(6): 935-944.

17. Zhang R, Shen L, Xie Y, Gen L, Li X, Ji Q (2013). Effect of morphine-induced postconditioning in corrections of tetralogy of fallot. J Cardiothorac Surg. 8: 76. doi: 10.1186.

18. Scott CS, Riggs KW, Ling EW, Fitzgerald CE, Hill ML, Grunau RV, et al (1999). Morphine pharmacokinetics and pain assessment in premature newborns. J Pediatr.; 135(4): 423429.

19. Bouwmeester NJ, Anderson BJ, Tibboel D, Holford NHG (2004). Developmental pharmacokinetics of morphine and its metabolites in neonates, infants and young children. $\mathrm{Br} \mathrm{J}$ Anaesth; 92(2): 208-217.

20. Choonara IA, McKay P, Hain R, Rane A (1989). Morphine metabolism in children. Br J Clin Pharmacol.; 28(5): 599-604.

21. Christrup LL (1997). Morphine metabolites. Acta Anaesthesiol Scand. 41(1 Pt 2): 116-122.

22. Cone EJ, Heit HA, Caplan YH, Gourlay D (2006). Evidence of morphine metabolism to hydromorphone in pain patients chronically treated with morphine. J Anal Toxicol. 30(1): 1-5. 
23. Rudin A, Lundberg JF, Hammarlund-Udenaes M, Flisberg P, Werner MU (2007). Morphine metabolism after major liver surgery. Anesth Analg. 104(6): 1409-1414.

24. Heilmann S, Küchler S, Schäfer-Korting M (2012). Morphine metabolism in human skin microsomes. Skin Pharmacol Physiol.; 25(6): 319-322.

25. Beechinor RJ, Tyson R, Roth ME (2021). Phenelzine and Morphine Drug-Drug Interaction? A Literature Review. $J$ Pharm Pract.; 34(5): 818-823.

26. Hobl E-L, Reiter B, Schoergenhofer C, Schwameis M, Derhaschnig U, Lang IM, et al (2016). Morphine interaction with prasugrel: a double-blind, cross-over trial in healthy volunteers. Clin Res Cardiol.; 105(4): 349-355.

27. Bartko J, Schoergenhofer C, Schwameis M, Wadowski P, Kubica J, Jilma B, et al. (2018) Morphine Interaction with Aspirin: a Double-Blind, Crossover Trial in Healthy Volunteers. J Pharmacol Exp Ther. 365(2): 430-436.

28. Vaidya GN, Khan A, Ghafghazi S (2019). Effect of morphine use on oral P2Y12 platelet inhibitors in acute myocardial infarction: Meta-analysis. Indian Heart J. 71(2): 126-135.

29. Webb A, Leong S (2005). The combination of tramadol and morphine may be recommended for postoperative analgesia. Anesth Analg.; 101(6): 1884-1885.

30. Karakucuk EH, Yamanoglu T, Demirel O, Bora N, Zengil H (2006). Temporal variation in drug interaction between lithium and morphine-induced analgesia. Chronobiol Int. 23(3): 675-682.

31. Hobl E-L, Reiter B, Schoergenhofer C, Schwameis M, Derhaschnig U, Kubica J, et al (2016). Morphine decreases ticagrelor concentrations but not its antiplatelet effects: a randomized trial in healthy volunteers. Eur $J$ Clin Invest.46(1): 7-14.

32. Gilron I, Bailey JM, Tu D, Holden RR, Weaver DF, Houlden RL (2005). Morphine, gabapentin, or their combination for neuropathic pain. N Engl J Med.; 352(13): 1324-1334.

33. Parodi G, Bellandi B, Xanthopoulou I, Capranzano P, Capodanno D, Valenti R, et al (2014). Morphine is associated with a delayed activity of oral antiplatelet agents in patients with ST-elevation acute myocardial infarction undergoing primary percutaneous coronary intervention. Circ Cardiovasc Interv.; 8(1): e001593. doi: 10.1161.

34. Zimmermann U, Rudin C, Duò A, Held L, Bucher HU (2020). Treatment of opioid withdrawal in neonates with morphine, phenobarbital, or chlorpromazine: a randomized double-blind trial. Eur J Pediatr. 179(1): 141-149.

35. Burke S, Beckwith AM (2017). Morphine Versus Methadone Treatment for Neonatal Withdrawal and Impact on Early Infant Development. Glob Pediatr Health.; 4:2333794X17721128. doi: 10.1177.

36. Xiao F, Yan K, Zhou W (2019). Methadone versus morphine treatment outcomes in neonatal abstinence syndrome: A metaanalysis. J Paediatr Child Health.; 55(10): 1177-1182.
37. Brown MS, Hayes MJ, Thornton LM (2015). Methadone versus morphine for treatment of neonatal abstinence syndrome: a prospective randomized clinical trial. J Perinatol. 35(4): 278-283.

38. Nayeri F, Sheikh M, Kalani M, Niknafs P, Shariat M, Dalili $\mathrm{H}$, et al (2015). Phenobarbital versus morphine in the management of neonatal abstinence syndrome, a randomized control trial. BMC Pediatr.15: 57. doi: 10.1186.

39. Bada HS, Sithisarn T, Gibson J, Garlitz K, Caldwell R, Capilouto G, et al (2015). Morphine versus clonidine for neonatal abstinence syndrome. Pediatrics.; 135(2): e383-e391.

40. Mazurier E, Cambonie G, Barbotte E, Grare A, Pinzani V, Picaud JC (2008). Comparison of chlorpromazine versus morphine hydrochloride for treatment of neonatal abstinence syndrome. Acta Paediatr.; 97(10): 1358-1361.

41. MacGregor R, Evans D, Sugden D, Gaussen T, Levene M (1998) Outcome at 5-6 years of prematurely born children who received morphine as neonates. Arch Dis Child Fetal Neonatal Ed.; 79(1): F40-F43.

42. Wang J, Cai B, Huang D-X, Yang S-D, Guo L (2012). Decreased analgesic effect of morphine, but not buprenorphine, in patients with advanced P-glycoprotein ${ }^{+}$ cancers. Pharmacol Rep.; 64(4): 870-877.

43. Cohen SP, Dawson TC (2002). Nebulized morphine as a treatment for dyspnea in a child with cystic fibrosis. Pediatrics. 110(3): e38. doi: 10.1542.

44. De Gregori S, De Gregori M, Ranzani GN, Allegri M, Minella C, Regazzi M (2012). Morphine metabolism, transport and brain disposition. Metab Brain Dis.; 27(1): 1-5.

45. Ederoth P, Tunblad K, Bouw R, Johan C, Lundberg F, Ungerstedt U, et al (2004). Blood-brain barrier transport of morphine in patients with severe brain trauma. $\mathrm{Br} \mathrm{J}$ Clin Pharmacol.; 57(4): 427-435.

46. Bonnardot JP, Maillet M, Colau JC, Millot F, Deligne P (1982). Maternal and fetal concentration of morphine after intrathecal administration during labour. Br J Anaesth.; 54(5): 487-489.

47. Szeto HH, Umans JG, McFarland J (1982). A comparison of morphine and methadone disposition in the maternal-fetal unit. Am J Obstet Gynecol. 143(6): 700-706.

48. Kopecky EA, Simone C, Knie B, Koren G (1999). Transfer of morphine across the human placenta and its interaction with naloxone. Life Sci. 65(22): 2359-2371.

49. Robieux I, Koren G, Vandenbergh H, Schneiderman J (1990). Morphine excretion in breast milk and resultant exposure of a nursing infant. J Toxicol Clin Toxicol.;28(3):365-370.

50. Feilberg VL, Rosenborg D,Christensen CB, Mogensen JV (1989). Excretion of morphine in human breast milk. Acta Anaesthesiol Scand.33(5): 426-428. 